\author{
Marquette University \\ e-Publications@Marquette
}

6-2019

\title{
Effects of E-Cigarette Health Warnings and Modified Risk Ad Claims on Adolescent E-Cigarette Craving and Susceptibility
}

J. Craig Andrews

Marquette University, craig.andrews@marquette.edu

Darren Mays

Georgetown University Medical Center

Richard G. Netemeyer

University of Virginia - Main Campus

Scot Burton

University of Arkansas

Jeremy Kees

Villanova University

Follow this and additional works at: https://epublications.marquette.edu/market_fac

Part of the Marketing Commons

\section{Recommended Citation}

Andrews, J. Craig; Mays, Darren; Netemeyer, Richard G.; Burton, Scot; and Kees, Jeremy, "Effects of ECigarette Health Warnings and Modified Risk Ad Claims on Adolescent E-Cigarette Craving and Susceptibility" (2019). Marketing Faculty Research and Publications. 254.

https://epublications.marquette.edu/market_fac/254 
Marquette University

e-Publications@Marquette

\section{Marketing Faculty Research and Publications/College of Business Administration}

This paper is NOT THE PUBLISHED VERSION; but the author's final, peer-reviewed manuscript. The published version may be accessed by following the link in the citation below.

Nicotine \& Tobacco Research, Vol. 21, No. 6 (June 2019): 792-798. DOI. This article is @ Oxford Academic and permission has been granted for this version to appear in e-Publications@Marquette. Oxford Academic does not grant permission for this article to be further copied/distributed or hosted elsewhere without the express permission from Oxford Academic.

\section{Effects of E-Cigarette Health Warnings and Modified Risk Ad Claims on Adolescent E- Cigarette Craving and Susceptibility}

\section{J Craig Andrews}

Department of Marketing, Marquette University, Milwaukee, WI

Darren Mays

Lombardi Comprehensive Cancer Center, Georgetown University Medical Center, Washington, DC Richard G Netemeyer

McIntire School of Commerce, University of Virginia, Charlottesville, VA

Scot Burton

Department of Marketing, University of Arkansas, Fayetteville, AR

Jeremy Kees

Department of Marketing, Villanova University, Villanova, PA 


\section{Abstract \\ Introduction}

A between-subjects experiment examines the effects of different warning types and modified risk ecigarette ad claims on adolescent e-cigarette craving and future e-cigarette susceptibility for two different themes. One theme focuses on nicotine and addiction, and the other on the effects of potentially harmful constituents (eg, flavored chemicals and lung disease).

\section{Methods}

The effects of warning type (control, text-only, graphic health warning [GHW] and text) and modified risk e-cigarette ad claims (control, exposure reduction, risk reduction) are tested experimentally with two different arms (themes) for a sample of 1011 adolescents who had tried either e-cigarettes or cigarettes.

\section{Results}

For addiction, the text-only warning led to significantly less e-cigarette susceptibility than the no warning control condition. As expected, there were no differences between the $\mathrm{GHW}+$ text condition and text-only or control conditions for e-cigarette craving. An interaction between warning type and modified risk claims revealed significantly fewer e-cigarette cravings and less susceptibility for the textonly warning and no claim (control) condition than for any other condition. For fatal lung disease, the GHW + text condition led to fewer e-cigarette cravings and less susceptibility than the text-only warning and no warning (control) conditions.

\section{Conclusions}

Warning type effects can be very different under different themes (eg, addiction, fatal lung disease). In general, our results point to the effectiveness of the text-only warning for addiction and GHW + text for fatal lung disease. Relative exposure and risk modification claims (eg, less nicotine; less addicting) tend to undercut addiction warnings.

\section{Implications}

More than one type of e-cigarette warning may be necessary as e-cigarette research evolves. Our results show different warning type effects (eg, text-only; GHW + text) on e-cigarette craving and future susceptibility for adolescent experimenters depending on the risk theme (eg, addiction; lung disease) and presence of ad claims (eg, exposure and risk reduction). As research emerges on risks associated with e-cigarette use, it is important to first know what at-risk populations (eg, adolescents) believe about such risks. Such research will aid our understanding of what types of warnings might be most effective, especially in the presence of ad claims.

\section{Topic}

Nicotine, lung diseases, adolescent, addictive behavior, cigarettes, electronic cigarettes, craving

\section{Introduction}

As the single most preventable cause of death in the United States today, cigarette smoking causes about one of every five deaths in the United States, a total of almost 483000 deaths each year. ${ }^{1}$ This 
also is a global tragedy, contributing to some 7 million deaths worldwide. ${ }^{2}$ Smoking has been described accurately as a pediatric disease, as approximately $88 \%$ of current smokers begin smoking before age $18 .^{3-5}$ As nicotine is a highly addictive drug, smoking is very difficult to stop, with approximately $69 \%$ of current adult smokers trying and failing to quit. ${ }^{1}$ In the United States, the use of multiple tobacco products is growing, with $32 \%$ of adults using at least one tobacco product, even though only $18 \%$ are cigarette smokers. ${ }^{6}$ The trend toward dual- or poly-use is a concern for young experimenters, especially for new tobacco products, such as e-cigarettes (e-cigs), vaping tanks, and hookah. In fact, one-third of youth now perceive e-cigarettes as less harmful than conventional cigarettes, ${ }^{7}$ and ecigarette use among high school students (11.3\%) now is more prevalent than combustible cigarette smoking (8.0\%). ${ }^{8}$ In conjunction with recent aggressive advertising and promotion of new tobacco products, ${ }^{9}$ adolescents may be particularly susceptible to such products in future experimentation and use.

Recently, adolescents exposed to e-cigarette advertising reported a significantly greater likelihood of ecigarette use compared to control groups. ${ }^{10}$ Other research shows an association of e-cigarette use by adolescents with subsequent initiation of traditional cigarette use. ${ }^{11}$ In a sample of 12 e-cigarette brands, levels of toxicants in e-cigarettes are found to be 9-450 times lower than cigarette smoke. Yet, they still contain significantly higher levels of six carcinogenic and toxic compounds (eg, formaldehyde, acetaldehyde, nitrosamines, cadmium, nickel, and lead) in comparison with the Nicorette inhaler. ${ }^{12}$ As e-cigarettes vaporize a propylene glycerol solution containing nicotine, a text addiction warning will be required for advertising and packaging. ${ }^{13}$ Users of e-cigarettes also risk respiratory exposure and potential lung disease due to aerosolized chemicals, including solvents, flavorants, adulterants, and other toxicants in the heating/aerosolization process. ${ }^{14}$

The Family Smoking Prevention and Tobacco Control Act (FSPTCA) ${ }^{3}$ was signed in law on June 22, 2009 giving the FDA authority to regulate the manufacture, marketing, and distribution of tobacco products in the United States (Sec. 901). Several interesting provisions of the Family Smoking Prevention and Tobacco Control Act include the use of modified risk tobacco products (MRTPs) and claims (Sec. 911 for e-cigarettes), proposed graphic health warnings (GHWs) (Sec. 201), disclosure of harmful constituents (Sec. 206), and the role of tobacco education to aid prevention and cessation. ${ }^{15,16}$ In its "deeming rule" extending its authority over all tobacco products, the FDA included a requirement for a nicotine warning regarding addiction. ${ }^{13,14}$ Also, there are two types of modified risk orders granted from the FDA for MRTPs: (1) a risk modification order (for products showing a significant reduction of harm and risk of tobacco-related disease) or (2) an exposure modification order (for products not shown to reduce risk/disease, yet are likely to do so because of a substantial reduction in exposure to harmful substances). For exposure modification products, consumers are not to be misled by the products' labeling/marketing into believing that the product is less harmful than commercially marketed tobacco products. For example, an exposure claim of "fewer chemicals" may not be interpreted by consumers as meaning low (carcinogenic) risk or lower risk versus other cessation products. For risk modification claims ("fewer cancer-causing chemicals"), the applicant must demonstrate that the product will significantly reduce harm and risk of tobacco-related disease and benefit population health. Yet, the Institute of Medicine Report on MRTPs ${ }^{17}$ laments that "there is a dearth of credible and reliable evidence about MRTP safety, consumer perceptions, and individual and public health effects to guide federal regulatory decision." The FDA's MRTP Draft Guidance ${ }^{18}$ recommends that scientific studies as 
part of FDA MRTP applications include the ability of consumers to understand the modified risk claims and the health significance of the information. As e-cigarette ads have been making implicit and explicit risk claims, ${ }^{9}$ it is important to test warning information with such claims.

To date, there have been no studies of different warning types and MRTP claims for adolescent experimenters exposed to e-cigarette ads. Therefore, our primary research objective is to conduct an experimental test of warning types (control, text-only, GHW and text) and modified risk ad claims (control, exposure reduction, risk reduction) for their impact on adolescent e-cigarette craving, evoked fear, risk beliefs, and future e-cigarette susceptibility. In a randomized experiment, one theme focuses on nicotine and addiction, and the other theme examines effects of potentially-harmful constituents (eg, flavored chemicals and lung cancer).

In addition to testing modified risk claims, an important contribution of our study is the examination of different warning types, including text and GHWs. So far, the impact of GHWs have yet to be studied with e-cigarettes (see suggestions in Berry et al. ${ }^{19}$ and Wackowski et al. ${ }^{20}$ ). Although their use in the United States is currently blocked by a court ruling (unlike 109 other countries), considerable research on GHWs points to their effectiveness, ${ }^{21,22}$ for both adult ${ }^{23}$ and younger cigarette smokers. ${ }^{24-28}$ For example, in a study of dual pathways to persuasion from the GHWs, Andrews et al. ${ }^{24}$ found that both emotional responses (via evoked fear) and cognitive responses (via beliefs) affected quit thoughts. However, evoked fear was found to have a stronger effect than beliefs in mediating the effects of GHWs on quit thoughts for adolescent smokers, while this effect was reversed for young adult smokers. Moreover, research has shown that smoker attention and recall of health risk information is significantly improved with GHWs beyond that of text-only warnings. ${ }^{29}$

Still, one's prior knowledge and initial opinions can bias the scrutiny of externally-provided communications, ${ }^{30}$ such as with different harmful consequences and types of e-cigarette warnings. In the case of better known and more direct connections, such as the nicotine-addiction linkage, ${ }^{20}$ simple text warnings may be sufficient. However, in the case of emerging, yet potentially-harmful consequences of e-cigarette use, such as respiratory and lung disease problems, GHWs may be more effective, as shown in prior GHW research for combustible cigarettes. As one direct and widelyconveyed purpose of e-cigarettes is to reduce dependence on traditional cigarettes, exposure and risk modification claims regarding less nicotine and addiction are likely to undercut and counter the addiction warning. ${ }^{19,31}$ Yet, this is likely not the case for exposure and risk modification claims about fewer (cancer-causing) chemicals with longer-term lung disease consequences. Based on prior warning and claim research, and the different consequence themes, it is predicted that:

H1: For addiction: (a) Text-only warnings will lead to fewer e-cigarette cravings and less ecigarette susceptibility than for those exposed to a no warning (control) condition in e-cigarette ads. (b) No differences in e-cigarette craving and e-cigarette susceptibility are expected between the GHW + text condition versus the text-only condition.

H2: For addiction: (a) An interaction between modified risk claim type and warning type is expected such that fewer e-cigarette cravings and less e-cigarette susceptibility are expected for the text-only warning and no claim (control) condition than for any other treatment conditions in e-cigarette ads. 
H3: For fatal lung disease: (a) The GHW + text condition will lead to fewer e-cigarette cravings and less e-cigarette susceptibility than for those exposed to either the text-only warning condition or no warning (control) condition in e-cigarette ads. (b) No differences in e-cigarette craving and e-cigarette susceptibility are expected between the text-only warning and no warning (control) conditions. (c) An interaction between modified risk claim type and warning type is not expected for e-cigarette cravings and e-cigarette susceptibility.

\section{Methods}

\section{Sample and General Procedure}

\section{Data Collection}

A professional marketing research firm with expertise in adolescent smoking research was used to collect the data. A double consent procedure was employed, that is, parents were first contacted to obtain permission and then the adolescent participants were asked for permission. Participants in the pretest and main experiment were adolescents aged 13-18, who indicated that they had tried or experimented with either cigarettes or e-cigarettes or both in their lifetime $(80 \%$ were e-cigarette experimenters). ${ }^{32}$

\section{Pretest}

A pretest of 126 adolescents that had experimented with either cigarettes or e-cigarettes in their lifetime was used to help select the graphic visual warning from five pictures depicting addiction and then from five pictures depicting fatal lung disease (FLD) from around the world. Three age quotas (ie, 13-14, 15-16, and 17-18), based on the University of Michigan Monitoring the Future data on adolescent smokers, were used to help ensure representative samples in all adolescent age groups. A $50 / 50$ split was made on gender to ensure equal representation in the samples, and experimentation with cigarettes or e-cigarettes ${ }^{32}$ was screened as well. Each adolescent was exposed to a randomlyordered set of five pictures depicting an addiction theme and then a randomly-ordered set of five pictures showing a FLD theme. They then were asked a set of questions regarding perceived graphicness, evoked fear, fit with a text warning on addiction (or fatal lung disease) under each picture, and picture believability. For the key measure of graphicness, each respondent evaluated the given picture on four, 7-point scales: graphic-not graphic; vivid-not vivid; powerful-weak; and intense-not intense; average $\alpha=$.91). ${ }^{23,24} \mathrm{~A}$ single item, 7-point measure assessed the picture fit with a text warning of "addiction" (or "fatal lung disease"), and a second, 7-point measure assessed the perceived believability of the picture. The text warnings stated either: "WARNING: E-cigarettes are addictive" or "WARNING: E-cigarettes may case fatal lung disease." The level of evoked fear from each picture was measured with four, 7-point scales: fearful-not fearful; afraid-not afraid; anxious-not anxious; and nervous-not nervous; average $\alpha=.92) .{ }^{23,24}$ Standardized mean scores were calculated and confidence intervals within each theme showed pictures that were significantly different from one another ( $p \leq .05$ ). The graphicness and evoked fear results for addiction indicated that the picture showing smoking through a stoma hole was significantly more graphic and evoked more fear than the other four pictures tested. This picture also produced text warning fit $(M=5.98)$ and perceived believability $(M=6.12$ ) scores greater than the respective scale mid-points. For fatal lung disease, the graphicness and evoked fear measures indicated that the picture depicting before-after FLD on a white background was significantly more graphic and evoked greater fear than the other four pictures 
tested. This picture also resulted in text warning fit $(M=6.03)$ and perceived believability $(M=$ 6.03 ) scores greater than the respective scale mid-points.

The two claims in the addiction ads (ie, for exposure modification: "Less Nicotine, More Freedom"; for risk modification: "Less Nicotine, Less Addicting, More Freedom") and two claims in the FLD ads (ie, for exposure modification: "Fewer Chemicals, More Freedom"; for risk modification: "Fewer CancerCausing Chemicals, More Freedom") were tested for claim strength (A control claim just mentioned "More Freedom" in the ad). Claim strength was measured on 7-point scales with the following five items: weak-strong, unpersuasive-persuasive, not convincing-convincing, a bad claim-a good claim, not believable-believable ${ }^{33}$; all $\alpha>$.94). Mean values for claim strength for all four ad claims were above 5 on the 7-point scale.

\section{Main Study Procedure, Sample and Design}

The main experiment again used a double consent procedure (ie, parents gave their permission, then adolescent participants) before being screened on age, gender, and use of either cigarettes or ecigarettes in their lifetime (80\% had used e-cigarettes). The total study sample consisted of 1011 adolescents experimenting with smoking ${ }^{32}$ with quotas producing a 50/50 split on gender and age categories of 15\% (13-14 years), 33\% (15-16 years), and 52\% (17-18 years) based on the University of Michigan Monitoring the Future data. Following screening questions, respondents were told they first would be answering some questions about cigarettes and electronic cigarettes, "...also known as ecigarettes, e-cigs, cig-alikes, personal vaporizers, or vapor cigs....". They also were told they would be viewing an e-cigarette ad. After successful screening for consent and quotas, respondents were randomly assigned to one of nine experimental versions of an e-cigarette ad for either addiction (Theme 1) or FLD (Theme 2). Based on the FDA e-cigarette deeming rules ${ }^{13}$ and the Family Smoking Prevention and Tobacco Control Act, ${ }^{3}$ the top center of the ad displayed the health warning (if included) and covered $20 \%$ of the ad space. The bottom portion displayed the ad claim (if made). The same warnings and ad claims discussed in the pretest were used in the main study experiments. Thus, each main study experiment used a 3 (warning type: absent/control, text-only, text + GHW) $\times 3$ (claim type: absent/control, exposure modification, risk modification) between-subjects design. The most widely-advertised electronic cigarette brand (blu) was used as a basis for ad stimuli. This brand recorded a $256 \%$ increase in youth TV ad target rating points over a recent 2-year period. ${ }^{9}$

\section{Main Study Measures}

Key dependent variables of interest included e-cigarette craving (single-item, 7-point scale) and future e-cigarette susceptibility (four-item, 7-point scale, $\alpha=.97$ ). Evoked fear (four-item, 7-point scale, $\alpha=.96)$ and risk beliefs (single-item, 7-point scale) also were assessed. E-cigarette craving was measured by asking respondents, "After having viewed the e-cigarette ad, how much do you want to smoke an e-cigarette right now?" with endpoints of "not at all"-“very much." ${ }^{25,34}$ The evoked fear measure asked respondents how the e-cigarette ad made them feel with endpoints of "not fearful""very fearful"; "not afraid"-"very afraid"; "not nervous"-"very nervous"; and "not anxious"-"very anxious." 23,24 For e-cigarette risk beliefs, respondents were asked whether "Using e-cigarettes can be additive" ("strongly disagree-strongly agree") and whether "Using e-cigarettes may increase the risk of fatal lung disease" ("strongly disagree-strongly agree"). Future e-cigarette susceptibility was measured on 7-point scales by the following: (1) "Do you think you will try an e-cigarette soon?" ("definitely not- 
definitely yes"), (2) "If you had the opportunity to try an e-cigarette today, how likely would you do it?" ("not at all likely-very likely"), (3) "If one of your best friends offered you an e-cigarette, would you try it?" ("definitely not-definitely yes"), and (4) "Do you think you will try an e-cigarette in the next year?" ("definitely not-definitely yes"). ${ }^{24,32,35}$

\section{Results}

A manipulation check assessed the graphic level of the ads. Those exposed to the GHW condition $(M=5.05)$ felt the warning was significantly more graphic (on the four, 7-point scales used in the pretest) than those exposed to either the text-only warning $(M=4.50)$ or control conditions $(M=$ 3.55; $F=65.01 ; p \leq .01$ ). The means (and lower bound of 95\% confidence intervals) for the believability and credibility of the text box information, as well as for the ad claim information, were all above 4.7 and the mid-point (4) of the scales.

For both the addiction and lung disease themes, a multivariate analysis of covariance (MANCOVA) was conducted to examine main effects for warning type, ad claim type, and interaction effects between the warning and claim types. Age and gender served as covariates. All adolescents had indicated that they had either smoked a cigarette or tried/experimented with smoking a cigarette in their lifetime, ${ }^{32}$ and $80 \%$ had experimented with e-cigarettes. Table 1 shows the overall multivariate and univariate findings for the addiction theme, as well as the marginal means and standard deviations for each independent variable for this theme. Table 2 displays the same analysis, but for the FLD theme. 
Table 1. Multivariate and Univariate Results: Adolescent Experimenters: Addiction

\begin{tabular}{|c|c|c|c|c|c|c|}
\hline & $\begin{array}{l}\text { MANCOVA } \\
\text { results }\end{array}$ & & $\begin{array}{l}\text { Univariate } \\
\text { results }\end{array}$ & & & \\
\hline Independent variables & Wilks' $\lambda$ & $F$-value & $\begin{array}{l}\text { E-cigarette } \\
\text { craving }\end{array}$ & Evoked fear & $\begin{array}{l}\text { Addiction } \\
\text { belief }\end{array}$ & $\begin{array}{l}\text { E-cigarette } \\
\text { susceptibility }\end{array}$ \\
\hline \multicolumn{7}{|l|}{ Main effects } \\
\hline Warning type (W) & 0.92 & $4.95 * * *$ & 2.09 & $11.86^{* * *}$ & $7.94 * * *$ & $3.20 * *$ \\
\hline Claim type (C) & 0.99 & 0.69 & 1.64 & 0.45 & 0.71 & 0.70 \\
\hline \multicolumn{7}{|l|}{ Interaction effects } \\
\hline $\mathrm{W} \times \mathrm{C}$ & 0.94 & $2.02 * * *$ & $3.36 * * *$ & 1.61 & 1.57 & $3.43 * * *$ \\
\hline \multicolumn{7}{|c|}{$\begin{array}{l}\text { Means (and Standard Deviations) for } \\
\text { the Effects of Warning Type (W) and } \\
\text { Claim Type (C) Conditions on } \\
\text { Adolescent Experimenters: Addiction }\end{array}$} \\
\hline & & & $\begin{array}{l}\text { E-cigarette } \\
\text { craving }\end{array}$ & Evoked fear & $\begin{array}{l}\text { Addiction } \\
\text { belief }\end{array}$ & $\begin{array}{l}\text { E-cigarette } \\
\text { susceptibility }\end{array}$ \\
\hline \multicolumn{7}{|l|}{ Warning type } \\
\hline Control (a) & & & $4.11(2.02)$ & $2.67(1.58)^{b, c}$ & $4.93(1.69)^{b, c}$ & $4.19(1.98)^{b}$ \\
\hline Text only (b) & & & $3.72(2.02)$ & $3.39(1.78)^{a}$ & $5.52(1.41)^{a}$ & $3.66(2.04)^{a}$ \\
\hline Text + graphic (c) & & & $3.68(1.91)$ & $3.38(1.81)^{a}$ & $5.53(1.51)^{a}$ & $3.97(2.08)$ \\
\hline \multicolumn{7}{|l|}{ Claim type } \\
\hline Control (a) & & & $3.70(2.05)$ & $3.18(1.79)$ & $5.37(1.56)$ & $3.86(2.07)$ \\
\hline Exposure mod (b) & & & $3.76(1.90)$ & $3.06(1.76)$ & $5.41(1.51)$ & $3.86(2.04)$ \\
\hline Risk mod (c) & & & $4.06(2.03)$ & $3.18(1.72)$ & $5.17(1.63)$ & $4.10(2.02)$ \\
\hline
\end{tabular}

MANCOVA = multivariate analysis of covariance; SNK = Student-Newman-Keuls. In the lower panel, comparisons are made going down a column.

Superscripts adjacent to the means for a given column in the table indicate significant differences ( $p \leq .05$ or better) according to SNK contrasts based on predictions. For example, for the evoked fear column and comparing warning types, the superscript for the " $c$ " cell (Text + graphic) indicates that the evoked fear mean is significantly greater than the mean for the control cell labeled "a".

${ }^{*} p<.10 ;{ }^{*} p<.05 ;{ }^{* *} p<.01, N=491$. Other interactions are nonsignificant for all dependent measures. Covariates $=$ age, gender. 
Table 2. Multivariate and Univariate Results: Adolescent Experimenters: Fatal Lung Disease (FLD)

\begin{tabular}{|c|c|c|c|c|c|c|}
\hline & $\begin{array}{l}\text { MANCOVA } \\
\text { results }\end{array}$ & & $\begin{array}{l}\text { Univariate } \\
\text { results }\end{array}$ & & & \\
\hline Independent variables & Wilks' $\lambda$ & F-value & $\begin{array}{l}\text { E-cigarette } \\
\text { craving }\end{array}$ & Evoked fear & FLD belief & E-cigarette susceptibility \\
\hline \multicolumn{7}{|l|}{ Main effects } \\
\hline Warning type (W) & 0.84 & $10.73 * * *$ & $6.53 * * *$ & $29.37 * * *$ & $23.25^{* * *}$ & $6.53 * * *$ \\
\hline Claim type (C) & 0.99 & 0.93 & 0.80 & 1.28 & 0.38 & 1.77 \\
\hline \multicolumn{7}{|l|}{ Interaction effects } \\
\hline $\mathrm{W} \times \mathrm{C}$ & 0.98 & 1.53 & 0.55 & 0.57 & 0.21 & 1.36 \\
\hline \multicolumn{7}{|c|}{$\begin{array}{l}\text { Means (and Standard Deviations) } \\
\text { for the Effects of Warning Type (W) } \\
\text { and Claim Type (C) Conditions on } \\
\text { Adolescent Experimenters: Fatal } \\
\text { Lung Disease (FLD) }\end{array}$} \\
\hline & & & $\begin{array}{l}\text { E-cigarette } \\
\text { craving }\end{array}$ & Evoked fear & FLD belief & E-cigarette susceptibility \\
\hline \multicolumn{7}{|l|}{ Warning type } \\
\hline Control (a) & & & $4.05(2.08)^{\mathrm{c}}$ & $2.99(1.88)^{b, c}$ & $4.40(1.82)^{b, c}$ & $4.15(2.10)^{\mathrm{c}}$ \\
\hline Text only (b) & & & $3.98(2.12)^{c}$ & $3.89(1.91)^{a, c}$ & $5.22(1.68)^{a}$ & $4.00(2.14)^{c}$ \\
\hline Text + graphic (c) & & & $3.33(2.22)^{a, b}$ & $4.61(1.80)^{a, b}$ & $5.58(1.60)^{a}$ & $3.40(2.19)^{a, b}$ \\
\hline \multicolumn{7}{|l|}{ Claim type } \\
\hline Control (a) & & & $3.92(2.21)$ & $3.63(2.02)$ & $5.01(1.90)$ & $4.07(2.20)$ \\
\hline Exposure mod (b) & & & $3.66(2.07)$ & $3.99(1.92)$ & $5.02(1.75)$ & $3.64(2.08)$ \\
\hline Risk mod (c) & & & $3.82(2.13)$ & $3.79(1.97)$ & $5.10(1.68)$ & $3.89(2.19)$ \\
\hline
\end{tabular}

MANCOVA = multivariate analysis of covariance; SNK = Student-Newman-Keuls. In the lower panel, comparisons are made going down a column.

Superscripts adjacent to the means for a given column in the table indicate significant differences ( $p \leq .05$ or better) according to SNK contrasts based on predictions. For example, for the e-cigarette craving column and comparing warning types, the superscripts for the "c" cell (Text + graphic) indicate that the e-cigarette craving mean is significantly less than the mean for the cells labeled "a" and "b."

${ }^{*} p<.10 ;{ }^{*} p<.05 ;{ }^{* *} p<.01, N=486$. Other interactions are nonsignificant for all dependent measures. Covariates $=$ age, gender. 


\section{Theme 1: Addiction Effects for Warning Type}

Hypothesis 1a predicted that text-only warnings should result in fewer e-cigarette cravings and less ecigarette susceptibility than will a no warning (control) condition. Partially supporting $\mathrm{H} 1 \mathrm{a}$, our findings in Table 1 indicate that although warning type did not reach significance on e-cigarette craving $(F=$ 2.09, $p=.13)$, it had a significant effect on e-cigarette susceptibility $(F=3.20, p \leq .05)$. As shown in Table 1, Student-Newman-Keuls (SNK) contrasts indicate that the text-only warning $(M=$ 3.66) significantly reduced e-cigarette susceptibility for adolescent experimenters compared to no warning control $(M=4.11)$ condition $(p \leq .05)$. All null hypothesis significance tests were conducted with 95\% inferential confidence intervals using procedures outlined in Muthusamy et al. ${ }^{36}$ In Table 1, as predicted, there were no significant differences for e-cigarette craving between the GHW + text $(M=3.68)$ and text-only conditions $(M=3.72, p \geq .20)$ offering partial support for H1b. However, GHW + text condition ( $M=3.97)$ produced greater e-cigarette susceptibility than the text-only condition $(M=3.66)$.

\section{Addiction Theme Interaction Effects for Warning and Claim Types}

Hypothesis 2 predicted an interaction between warning type and modified risk ad claim type. It was expected that a greater reduction in e-cigarette craving and in e-cigarette susceptibility would occur for the text-only warning for no claim (control) condition, but this warning would be less effective when modified risk ad claims were made. The results in Table 1 and Figure 1 show a significant warning type $\mathrm{x}$ ad claim type effect for both e-cigarette craving $(F=3.36, p \leq .01)$ and e-cigarette susceptibility $(F=3.43, p \leq .01$ ) (As noted in Table 1 , this interaction was not significant for evoked fear and the addiction belief.). In support of $\mathrm{H} 2$, when the text-only warning was displayed, the no claim control ( $M=2.95$ ) led to significantly fewer e-cigarette cravings than found with the exposure modification claim $(M=3.92, p \leq .05)$ and risk modification claim conditions $(M=4.26, p \leq$ .05). Also, in support of $\mathrm{H} 2$, when the text-only warning was shown, the no claim control $(M=3.06)$ led to significantly less e-cigarette susceptibility than found with the risk modification claim conditions $(M=4.11, p \leq .05)$. The no claim control led to marginally significant and less e-cigarette susceptibility than the exposure modification claim condition $(M=3.78, p \leq .10)$. 
Figure 1. Effects of warning type and claim type on e-cigarette craving and susceptibility (addiction theme).

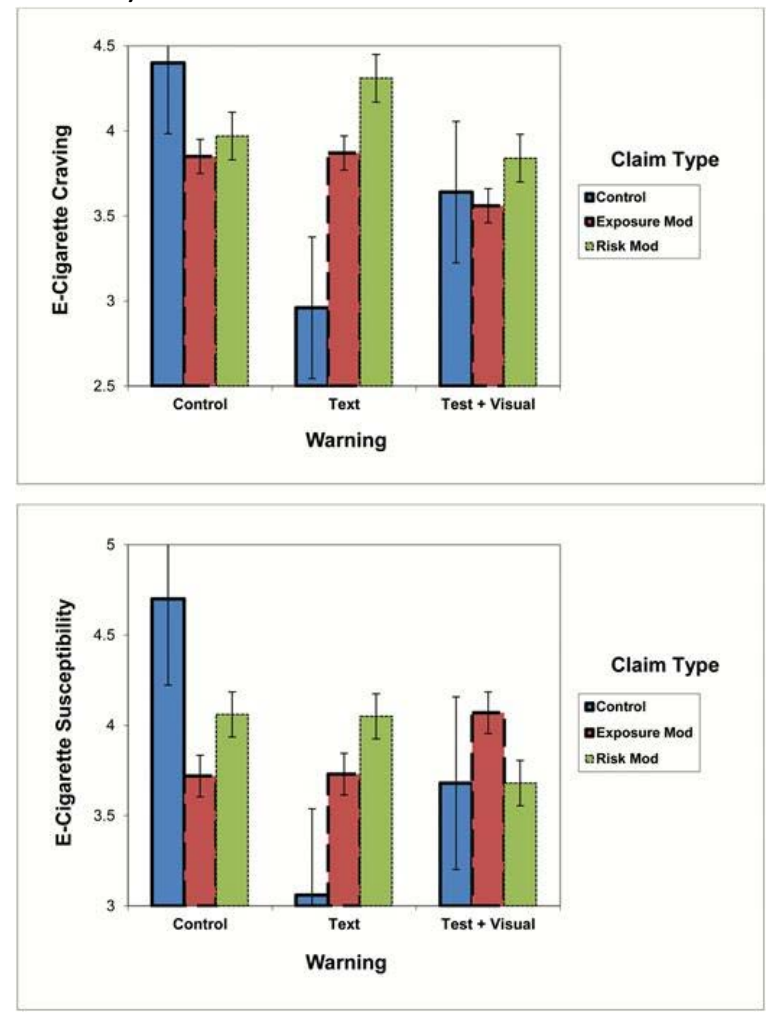

\section{Theme 2: FLD Effects for Warning Type}

For the FLD theme, there were main effects for warning type for both e-cigarette craving $(F=$ $6.53, p \leq .01)$ and e-cigarette susceptibility $(F=6.53, p<.01)$. In support of H3a, and found in Table 2, the GHW + text condition $(M=3.33)$ led to significantly fewer e-cigarette cravings than found with the text-only warning $(M=3.98, p \leq .05)$ and no control warning conditions $(M=$ $4.05, p \leq .05)$. Also, in support of $\mathrm{H3a}$, the $\mathrm{GHW}+$ text condition $(M=3.40)$ led to significantly less e-cigarette susceptibility than found with the text-only warning $(M=4.00, p<.05)$ and no control warning conditions ( $M=4.15, p<.05)$. In support of $\mathrm{H} 3 \mathrm{~b}$, and as noted in Table 2 , there were no differences between the text-only warning and no warning control conditions for both e-cigarette craving and susceptibility (Yet, as Table 2 reveals, both the GHW + text and text-only conditions significantly increased evoked fear and the FLD belief compared to the control condition.). In support of $\mathrm{H3c}$, there was not an interaction between warning type and the modified risk claim type, as the relatively strong effects of the GHW + text condition occurred across all claim types. Finally, a comparison of e-cigarette beliefs asked of all respondents in the no warning control condition revealed that their prior knowledge (ie, belief) regarding addiction and e-cigarette use $(M=4.93)$ was significantly greater than that for that of FLD and e-cigarette use $(M=4.38$; paired $t=6.85, p \leq$ $.01)$.

\section{Discussion}

Most experimental research on e-cigarette warnings has involved text-only conditions and not the GHWs, nor warnings in the presence of modified risk ad claims. Evidence exists that general health 
claims can undercut text-only warnings for adult smokers ${ }^{37}$ and nonsmokers. ${ }^{31}$ Yet, as noted in Wackowski et al., ${ }^{20}$ recent interviews with e-cigarette research experts reveal that "...more than one warning would be important as e-cigarette science evolves and that research on additional warning themes (eg, nicotine exposure, harmful constituents) and execution styles (including the use of pictorials)" is needed. Our research sought to address these shortcomings for an at-risk sample of over 1000 adolescent experimenters exposed to different warning types (eg, text-only, text + GHW, no warning control), different modified risk ad claims (eg, exposure reduction, risk reduction, no claim control), and for two separate e-cigarette themes (addiction, FLD).

Our results indicate that, for the addiction theme, the text-only warning led to significantly less ecigarette susceptibility than the no warning control condition. As predicted, there were no differences between the GHW + text condition and text-only condition for e-cigarette craving. However, the GHW + text warning led to greater e-cigarette susceptibility than the text-only condition. An interaction between warning type and modified risk claims revealed significantly fewer e-cigarette cravings and less susceptibility for the text-only warning and no claim (control) condition than for any other condition. In the case of the FLD theme, the GHW + text condition led to fewer e-cigarette cravings and less susceptibility than the text-only warning and no warning (control) conditions. For both the addiction and lung disease themes, the inclusion of the text and GHW + text warnings also increased risk beliefs and evoked fear, relative to the no warning control condition. These results support the inclusion of warning messages in e-cigarette ads and across different ad claim conditions.

\section{Limitations and Future Research Issues}

Our randomized experimental study manipulated e-cigarette warnings and modified risk ad claims shown to adolescent experimenters for two separate themes (addiction, lung disease); offering support for the study's internal validity. Yet, although the online exposure context, sample focus, stimuli tested, measures used, and parental and adolescent consents (to meet IRB requirements) are consistent with prior tobacco warning research, ${ }^{23,24}$ they could serve to limit the generalizability of findings. For example, further validation work with e-cigarette craving and susceptibility measures may be warranted. No doubt, there can be other e-cigarette warning themes to consider, other country samples, smoking frequencies/situations ${ }^{32}$ (eg, progression from experimenters to any 30-day use to daily smokers), different modified risk ad claims, and other e-cigarette brands and tobacco products to examine (eg, hookah, cigars, cigarillos, smokeless tobacco). ${ }^{38}$ Also, mediation analysis may reveal interesting pathways to e-cigarette susceptibility from the warning and ad claim types. Future research might consider using longitudinal data to examine any possible wear-out patterns. Efforts in this regard will help contribute to a better understanding of how at-risk adolescents will react to the provision of important e-cigarette information, like different warning types in the presence of modified risk claims - all with the ultimate objective of reducing youth dependence on tobacco.

\section{Conclusions and Policy Implications}

In previous GHW research, ${ }^{23,24}$ the level of graphicness proved to be important in affecting intentions to quit for adolescent smokers. Yet, considering emerging scientific evidence for e-cigarettes, we find that warning type effects, including that for GHWs, can be quite different under different focal themes (eg, addiction, FLD). One possible explanation for our results is that greater prior knowledge on addiction and e-cigarettes may have lessened GHW effects, indicating the sufficiency of text-only 
warnings, whereas less prior knowledge of FLD and e-cigarettes may have strengthened GHW effects relative to other warning types. An alternative explanation is that certain smoking diseases (eg, lung cancer, mouth cancer) may be easier to depict visually, evoke greater fear (as Table 2 indicates for lung disease), and are more congruent with text warning information than for other health risks, such as addiction. ${ }^{39}$ Also, we find that relative exposure and risk modification claims (eg, less nicotine; less addicting) tend to undercut addiction warnings. Due to the emerging research on e-cigarettes, it is important to first know exactly what at-risk populations believe about different harmful consequences of use, and perceptions of GHW visuals, to better understand what type of warning might be most effective, especially in the presence of ad claims. This is likely to be helpful in research by federal agencies (eg, FDA) and for those in public health in best conveying the most appropriate e-cigarette warnings to at-risk populations, such as susceptible youth.

\section{Funding}

Internal support was received from Marquette University Summer Faculty Fellowship and Kellstadt endowed funds.

\section{Declaration of Interests}

None declared.

\section{Acknowledgments}

The authors gratefully acknowledge Jenna Fanduzzi and Lee Wickert for help with the ad stimuli. All authors contributed equally to the planning, conduct, analysis, and submission of the study. Ethics approval: Marquette University Institutional Review Board.

\section{References}

1. Centers for Disease Control and Prevention. Youth and tobacco use. http://www.cdc.gov/tobacco/data_statistics/fact_sheets/youth_data/tobacco_use/index.htm. Accessed August 16, 2017.

2. World Health Organization. Tobacco: key facts. http://www.who.int/mediacentre/factsheets/fs339/en/. Accessed August 16, 2017.

3. Family Smoking Prevention and Tobacco Control Act (FSPTCA) (2009),Pub. Law No. 625110 U.S.C. § 900-302. Washington, DC: U.S. Congress; June 22.

4. Kessler DA, Natanblut SL, Wilkenfeld JP, et al. Nicotine addiction: a pediatric disease. J Pediatr. 1997;130(4):518-524.

5. Surgeon General Report. Preventing Tobacco Use Among Youth and Young Adults. Rockville, MD: U.S. Department of Health and Human Services; 2012.

6. Lee YO, Hebert CJ, Nonnemaker JM, Kim AE. Multiple tobacco product use among adults in the United States: cigarettes, cigars, electronic cigarettes, hookah, smokeless tobacco, and snus. Prev Med. 2014;62:14-19.

7. Ambrose BK, Rostron BL, Johnson SE, et al. Perceptions of the relative harm of cigarettes and ecigarettes among U.S. youth. Am J Prev Med. 2014;47(2 Suppl 1):S53-S60.

8. Jamal A, Gentzke A, Hu SS, et al. Tobacco use among middle and high school students - United States, 2011-2016. MMWR. 2017;66(23):597-603. 
9. Duke JC, Lee Y, Kim A, et al. Exposure to electronic cigarette television advertisements among youth and young adults. Pediatrics. 2014;134(1):1-8.

10. Farrelly MC, Duke JC, Crankshaw EC, et al. A randomized trial of the effect of e-cigarette TV advertisements on intentions to use e-cigarettes. Am J Prev Med. 2015;49(5):686-693.

11. Leventhal AM, Strong DR, Kirkpatrick MG, et al. Association of electronic cigarette use with initiation of combustible tobacco product smoking in early adolescence. JAMA. 2015;314(7):700-707.

12. Goniewicz ML, Knysak J, Gawron M, et al. Levels of selected carcinogens and toxicants in vapour from electronic cigarettes. Tob Control. 2013;23(2):133-139.

13. Federal Register. Deeming Tobacco Products To Be Subject to the Federal Food, Drug, and Cosmetic Act, as Amended by the Family Smoking Prevention and Tobacco Control Act; Restrictions on the Sale and Distribution of Tobacco Products and Required Warning Statements for Tobacco Products. Silver Spring, MD: U.S. Department of Health and Human Services, Food and Drug Administration; 2016;28973-29106.

14. Surgeon General Report. E-Cigarette Use Among Youth and Young Adults: A Report of the Surgeon General. Rockville, MD: U.S. Department of Health and Human Services; 2016.

15. Ashley DL, Backinger CL. The Food and Drug Administration's regulation of tobacco: the Center for Tobacco Products' Office of Science. Am J Prev Med. 2012;43(5 Suppl 3):S255-S263.

16. Husten CG, Deyton LR. Understanding the Tobacco Control Act: efforts by the US Food and Drug Administration to make tobacco-related morbidity and mortality part of the USA's past, not its future. Lancet. 2013;381(9877):1570-1580.

17. Institute of Medicine (IOM) Report. Scientific Standards for Studies on Modified Risk Tobacco Products, Report Brief. Washington, DC: Institute of Medicine; 2011.

18. FDA. Guidance for Industry: Modified Risk Tobacco Product Applications. Rockville, MD: U.S. Health \& Human Services, Food and Drug Administration, Center for Tobacco Products; 2012. http://www.fda.gov/downloads/TobaccoProducts/GuidanceComplianceRegulatorylnformation /UCM297751.pdf. Accessed August 16, 2017.

19. Berry C, Burton S, Howlett E. Are cigarette smokers', e-cigarette users', and dual-users' health-risk beliefs and responses to advertising influenced by addiction warnings and product type? Nicotine Tob Res. 2017;19(10):1185-1191.

20. Wackowski O, Hammond D, O'Connor R, et al. Considerations and future research directions for ecigarette warnings-findings from expert interviews. Intl J Env Res Public Health. 2017;14:781.

21. Hammond D, Fong GT, McNeil A, et al. Effectiveness of cigarette warning labels in informing smokers about the risks of smoking: findings from the International Tobacco Control (ITC) Four Country Survey. Tob Control. 2006;15(Suppl III):iii19-iii25.

22. Myers M [Media Release]. Government's Decision Not to Appeal Cigarette Warning Ruling Is Disappointing; FDA Should Quickly Develop New Set of Graphic Warnings. Washington, DC: Campaign for Tobacco-Free Kids; 2013. http://www.tobaccofreekids.org/press_releases /post/2013_03_19_fda. Accessed August 16, 2017.

23. Kees J, Burton S, Andrews JC, et al. Understanding how graphic pictorial warnings work on cigarette packaging. J Public Policy Mark. 2010;29(2):265-276.

24. Andrews JC, Netemeyer RG, Kees J, et al. How graphic visual health warnings affect young smokers' thoughts of quitting. J Marketing Res. 2014;51(2):165-183.

25. Andrews JC, Netemeyer RG, Burton S, et al. Effects of plain package branding and graphic health warnings on adolescent smokers in the United States, Spain, and France. Tob Control. 2016;25(e2):e120-e126. 
26. Mays D, Niaura RS, Evans WD, Hammond D, Luta G, Tercyak KP. Cigarette packaging and health warnings: The impact of plain packaging and message framing on young smokers. Tob Control. 2015;24(e1):e87-e92.

27. Pepper JK, Cameron LD, Reiter PL, et al. Non-smoking male adolescents' reactions to cigarette warnings. PLoS One. 2013;8(8):e65533.

28. Romer D, Peters E, Strasser AA, et al. Desire versus efficacy in smokers' paradoxical reactions to pictorial health warnings for cigarettes. PloS One. 2013;8(1):e54937.

29. Strasser AA, Tang KZ, Romer D, Jepson C, Cappella JN. Graphic warning labels in cigarette advertisements: recall and viewing patterns. Am J Prev Med. 2012;43(1):41-47.

30. Petty RE, Cacioppo JT. Communication and Persuasion: Central and Peripheral Routes to Attitude Change. New York, NY: Springer-Verlag; 1986.

31. Capella ML, Taylor CR, Kees J. Tobacco harm reduction advertising in the presence of a government-mandated warning. J Cons Aff. 2012;46(2):235-259.

32. Pierce JP, Choi WS, Gilpin EA, Farkas AJ, Merritt RK. Validation of susceptibility as a predictor of which adolescents take up smoking in the United States. Health Psychol. 1996;15(5):355-361.

33. Andrews JC. Tests of the Elaboration Likelihood Model Involving Persuasive Marketing Communications. Columbia, SC: University of South Carolina; 1985.

34. Wang A, Romer D, Elman I, et al. Emotional graphic cigarette warning labels reduce the electrophysiological brain response to smoking cues. Addict Biol. 2015;20(2):368-376.

35. Fishbein M, Ajzen I. Belief, Attitude, Intention, and Behavior: An Introduction to Theory and Research. Reading, MA: Addison-Wesley; 1975.

36. Muthusamy N, Levine T, Weber R. Scaring the already scared: Some problems with HIV/AIDS fear appeals in Namibia. J Comm. 2009;59:317-344.

37. Berry $C$, Burton S, Howlett E. The imact of e-cigarette addiction warnings and health-related claims on consumers' risk beliefs and use intentions. J Public Policy Mark. 2017;36(1):54-69.

38. Andrews JC, Choiniere JC, Portnoy DB. Opportunities for consumer research from the Food and Drug Administration's Center for Tobacco Products. J Public Policy Mark. 2015;34(1):119-130.

39. Lochbuehler K, Mercincavage M, Tang KZ, et al. Effect of message congruency on attention and recall in pictorial health warning labels. Tob Control. 2018;27:266-271. doi:10.1136/tobaccocontrol-2016-053615. 